\title{
Re-Thinking lighting system design based on visual comfort and energy performance
}

\author{
Z.A. Kılıç*iD, A. Köknel Yener (iD \\ Istanbul Technical University, Faculty of Architecture, Department of Architecture, Istanbul, Turkey
}

\begin{abstract}
Global warming and changing climatic conditions, as well as over-consumption of energy resources have led to the discussion of sustainable and energy-efficient approaches. The buildings have one of the most significant roles in over-energy consumption causing various global effects. Therefore, the importance of developing energy-efficient and energy-retrofit strategies in buildings has been increasing day by day. This study aims to introduce a sustainable lighting system design approach for new and refurbished buildings in terms of visual comfort and energy performance in accordance with the current standards. "TS EN 124641:2013 Light and lighting- Lighting of workplaces- Part 1: Indoor workplaces", which describes basic requirements for visual comfort and "TS EN 15193-1:2017 Energy Performance in Buildings - Energy requirements for lighting-Part 1: Specifications", which introduces a renewed and updated methodology to estimate lighting energy performance in buildings are used as the metrics for the approach offering to design sustainable lighting system. Office space for two people is selected as a sample in order to apply the developed approach. Obtaining results demonstrate that the lighting-retrofit design strategies have a great positive impact on visual comfort conditions and energy consumption in the office buildings, where energy use for lighting accounts for a huge proportion of the total energy consumption as well as providing visual comfort conditions is very important.
\end{abstract}

\section{Keywords}

Sustainable lighting system design; Energy retrofit; Energy performance; Visual comfort; Office building

Received: 25 November 2019; Accepted: 25 December 2019

ISSN: 2630-5771 (online) (C) 2019 Golden Light Publishing All rights reserved.

\section{Introduction}

Energy efficiency and sustainability are fundamental issues in architecture due to growing energy demand and excessive consumption of energy and other natural resources. According to studies, global energy demand increased by almost $2 \%$ in 2017 [1]. Moreover, global electricity demand increased by $3.1 \%$, significantly higher than the overall increase in energy demand [1]. Lighting energy consumption accounts for a significant portion of the electricity consumption.
Globally, almost one fifth of the total amount of electricity generated is consumed for lighting [2] On the other hand, it is a known fact that buildings consume a major part of the global energy reserve. The majority of the energy consumed in buildings is used to provide thermal and visual comfort through A/C systems (30-60\%) and artificial lighting (20-35\%) [3, 4]. In addition, lighting energy consumption especially in office buildings accounts for about $25 \%$ of the total electricity consumed depending on building typology and

* Corresponding author

Email: kilicze@itu.edu.tr 
intended use [5]. Because of all these reasons, studies to develop suggestions about energy-retrofit approaches in existing buildings and energy efficient solutions in new buildings have become more important.

In a study based on the literature review by Dubois etc., the importance of energy-retrofit lighting strategies is highlighted by taking into consideration potential of lighting energy saving in the total energy consumption of the buildings. They are also said that retrofit lighting design strategies can be conducted in 5 categories; Lamp, Ballast, Luminaire Replacement; Task/Ambient Lighting Design; improvement in maintenance; reduction of maintained illuminance levels; Improvement in spectral quality of light sources; improvement in occupant behaviour; Use of Control System and Use of Daylighting System [6]. Similarly, in the research, which examines energy saving strategies and their potential for lighting systems in office building located especially in North-European countries, it is clearly stated that designing a lighting system by chancing the lamp type (T12) with the other having high efficiency (T5), using a combination of more energy-efficient luminaries, integrated lighting concept, occupancy switch-off and daylight dimming can provide totally $80 \%$ energy saving compared to the standard fixed lighting system [7].

Work environments, where the actions require high visual performance and which are occupied for the majority of the day is one of the most important spaces that need a meticulous design to ensure visual comfort conditions and minimize energy consumption. Maintaining visual comfort conditions and achieving high visual performance, which is characterized as fast and correct execution of work that requires good vision is the priority for designing a lighting system in the office spaces. Any discomfort in visual performance in office spaces causes physical and psychological disturbances for people, decreasing in employee productivity. Therefore, providing visual comfort conditions and creating a visually pleasant environment are among the most important parameters to create a sustainable lighting system.
On the other hand, artificial lighting system is required in office spaces because of long working hours during the day, inadequate daylight availability or high illuminance levels required to perform the work. In this sense, It is very important that design decisions for a building starting from the conceptual design stage should be evaluated in terms of visual comfort and energy performance in order to achieve optimum performance in the lighting system. Decisions regarding the daylighting system, determining or reviewing the elements of artificial lighting system, as well as selection of appropriate control systems must be meticulously examined. In this sense, it has been demonstrated by various studies that up to $60 \%$ energy conservation can be achieved for lighting energy consumption by using daylighting strategies [8-10]. The potential of the control system on lighting energy saving have been also investigated in a number of studied [11-14]. These studies show that by using daylight control strategies, lighting energy consumption can be reduced by a minimum of $20 \%-30 \%$ and a maximum of $50 \%-60 \%$ $[12,13]$. On the other hand, designing a lighting system taking into consideration performance needs and re-designing the artificial lighting system by changing new technologies lighting installations are some of the best strategies in order to achieve an energy-efficient lighting system. Many studies on the subject indicate that the energy consumption of the lighting system is greatly diminished by using the new technologies lamps, ballast or luminaries having developed in recently [15-17]. Moreover, Linhart etc, have demonstrate that the higher visual performance and better visual comfort in the office space can be achieved with low lighting power density value contrary to the general belief by comparing test-office space having low LPD value $(3.9 \mathrm{~W} / \mathrm{m} 2)$ and reference- office space having $4 \mathrm{~W} / \mathrm{m} 2 \mathrm{LDP}$ value [18].

Reviewing all of the given above comprehensive knowledge, This study introduces an approach to design a sustainable lighting system that combines a pleasant visual environment and energy-efficient lighting strategies in the scope of the updated standards; TS EN 12464-1:2013 'Light 
and lighting- Lighting of work places- Part 1: Indoor work places', and TS EN 15193-1:2017 'Energy Performance in Buildings - Energy requirements for lighting-Part 1: Specifications'. Also, the study aims to offer the framework to display how these standards can help to design or retrofit the artificial lighting system for providing energy-efficient lighting system with a visuallypleasant environment to the designers.

According to the approach, Visual comfort conditions of the space are evaluated according to the standard 'TS EN 12464-1:2013 Light and lighting- Lighting of work places- Part 1: Indoor work places' which describes basic requirements for visual comfort in general and specifies recommended values to maintain illuminance, glare control, uniformity and colour rendering related to the function of the space. In cases where visual comfort conditions are provided, energy performance of the lighting system is evaluated according to the standard 'TS EN 15193-1:2017 Energy Performance in Buildings - Energy requirements for lighting-Part 1: Specifications' which estimates lighting energy demand in buildings taking into consideration installed power, daylight dependency and control strategies.

\section{Lighting system design considering visual comfort and energy performance}

Sustainable lighting design meets the qualitative requirements of the visual environment, with the least impact on the physical environment [19]. In this sense, a sustainable lighting system is possible by ensuring indoor visual comfort conditions and enhancing lighting energy efficiency. To optimize the lighting design solutions, which provide visual comfort and minimize energy consumption, the lighting system also should be evaluated in terms of protecting eye health both physiologically and psychologically and meeting aesthetic expectations as well.

A sustainable lighting system in a building or space describes the minimum energy consumption for lighting in order to fulfil visual comfort conditions. In the other words, ensuring indoor visual comfort conditions is a prerequisite to evaluate energy performance of any lighting system for designing the sustainable lighting system. Therefore, maintaining the identified recommendations at the required levels in the standards and applying the detailed calculation steps given for energy estimations are necessary and important to determine the sustainable lighting system design alternative that provides the optimum performance in terms of visual comfort and energy efficiency among the design options. In order to create a visually-health based lighting system that provides visual comfort conditions and an energy efficient lighting system that improves energy performance for new and existing buildings, the new approach given in Fig. 1 is suggested in scope of the study.

According to the approach shown in Fig. 1; firstly, the lighting system design proposal are developed, and the proposed lighting system in the space is examined whether the visual comfort parameters are met. These parameters change depending on the illuminance level (Em), glare index (UGR), uniformity (Uo) and colour rendering index (Ra) determined by the function of the space given in TS EN 12464-1: 2013 [20]. The illuminance level in a space is evaluated taking into consideration illuminance on the task area and immediate surrounding area in accordance with the TS EN 12464-1: 2013 as well. The façade properties, interior design (the materials of the surfaces, the place of the furniture etc.) and shading device type in relation to the indoor daylight availability also affect the visual comfort conditions in a space. Unless the visual comfort conditions can be provided by the proposed lighting system, the design proposal or existing lighting system should be revised until the visual comfort conditions are met. If it is fulfilled with the proposed lighting system, the energy performance of the lighting system is determined according to the lighting energy system parameters, which are the installed power, the daylight dependency and control strategy given in TS EN 15193-1: 2017 [21]. 


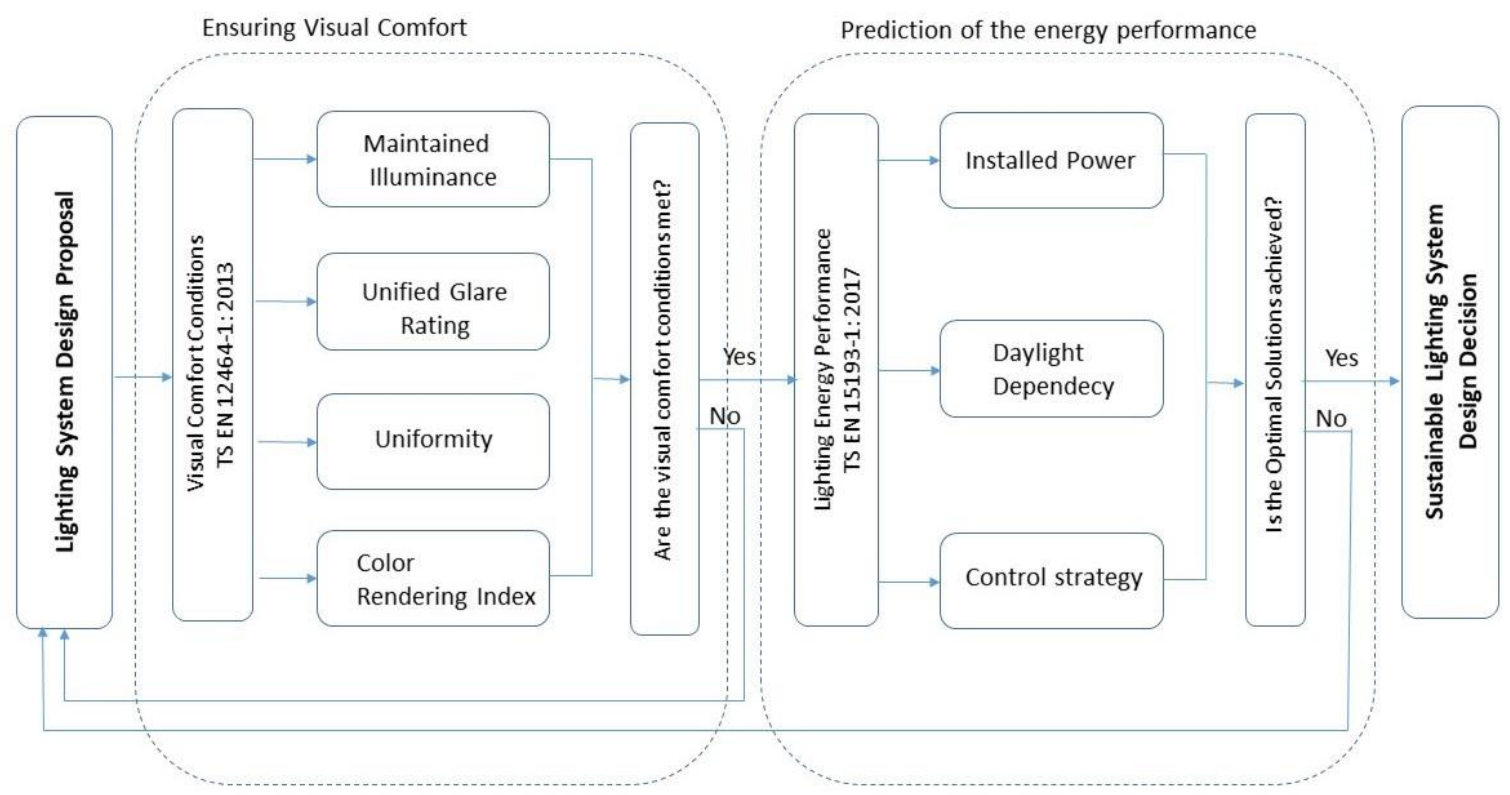

Fig. 1. Lighting system design approach for visual comfort and energy performance in accordance with the standards

If the optimal solution is achieved in terms of both visual comfort conditions and energy consumption for lighting, the final design decision is considered as a sustainable lighting system decision. On the contrary, the proposed lighting system design should be reviewed by considering all of the parameters affecting visual comfort and lighting energy performance.

For developing a sustainable lighting system, it is necessary to evaluate the energy performance of the lighting system after the visual requirements are met by examining the visual comfort parameters. Annual lighting energy requirements for any space or unit of a building is calculated by using Eq. (1) described in the standard TS EN 15193-1: 2017 [21].

$W_{L, t}=\left\{\left(P_{n} x F_{c}\right) \times\left[\left(t_{D} x F_{o} x F_{D}\right)+\left(t_{N} x F_{o}\right)\right]\right\} / 1000$ $(k W h)$

$P_{n}$ refers to the total installed power, which changes depending on the power of the luminaire(s) in the lighting system. $F_{c}$ is a value of the dimmable lighting control system, which provides a constant illuminance level in spaces. $t_{D}$ and $t_{N}$ values refer to the occupancy hours during daytime and daylight absence time depending on the type of space. $t_{D}$ and $t_{N}$ values are given for different typologies in the standard. Occupancy dependency factor $\left(\mathrm{F}_{\mathrm{o}}\right)$ is found according to the $F_{a}$ value which is determined according to the lighting system control type and space function and referred to absence factor. Daylight dependency factor $\left(\mathrm{F}_{\mathrm{D}}\right)$ which refers to a reduction in lighting energy requirement during daylight hours based on indoor daylight availability is included in calculations depending exterior obstacles, opening sizes, space dimensions, window characteristics and presence of a sun control device. Daylight dependency factor is calculated using the formula in the following Eq. (2) [21].

$\mathrm{F}_{\mathrm{D}}=1-\left(\mathrm{F}_{\mathrm{D}, \mathrm{S}} \times \mathrm{F}_{\mathrm{D}, \mathrm{C}}\right)$

In order to determine the daylight dependency factor $\left(F_{D}\right)$, firstly, the daylight factor of the raw building carcass opening $\left(\mathrm{D}_{\mathrm{C}}\right)$, which refers to the indoor daylight availability, is calculated and then daylight availability classification of the space is determined based on this value. Daylight supply factor $\left(F_{D, S}\right)$ value which is calculated using two different factors for the periods in which shading elements are active and inactive is shown in the tables depending on various variables. These variables are: latitude, relevant daylight factor (D), luminous exposure value based on the latitude and 
longitude to include the climate factor, maintained illuminance required in the space $\left(\mathrm{E}_{\mathrm{m}}\right)$ and solar control strategy. Another important variable about the presence of daylight dependency factor $\left(\mathrm{F}_{\mathrm{D}}\right)$ is the lighting control factor $\left(\mathrm{F}_{\mathrm{D}, \mathrm{C}}\right)$ depending on daylight. It is determined depending on whether the artificial lighting control system is manual or automatic, the daylight availability classification of the space and maintained illuminance required in the space.

In this study, an approach is developed in accordance with the standards, which provide updated and detailed evaluation method for energy efficient lighting systems that provide visual comfort conditions. Considering visual requirements and lighting energy consumption in workspaces, the aim is to evaluate office spaces for improving both visual comfort conditions and energy performance and to develop new lighting design options.

\section{Case study: Lighting system design for an office space in accordance with the developed approach}

In this section of the study, the lighting system of an office space for two people is evaluated according to the suggested approach. First, the existing lighting system of the office space is investigated in order to describe the existing visual conditions and energy performance. Second, a new lighting system design providing the visual comfort conditions and improving the energy performance for the workspace is developed.

\subsection{Variables concerning the office space and the calculations}

The private office for two people is selected as a sample space. The building, of which the investigated office space is the part, is located in Ankara, and has 4 floor including garden floor, entrance floor, first floor and roof floor. The investigated office space is at the 1th floor of the project office building. Fig. 2 shows the plan, section and a model of the private office space for two people.

The office space has no external obstacles, and there are three apertures in the space; one opening on the south direction that is the main aperture, the others are on the east and west directions. The variables about the office space and facade, which affect daylight availability and visual comfort conditions in the space, are shown in Table 1.

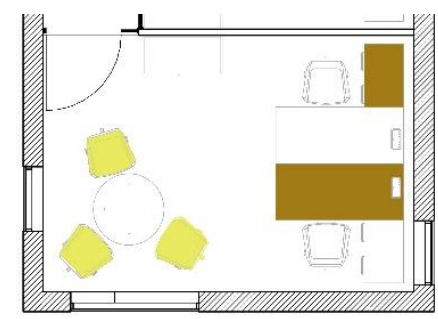

(a) Plan

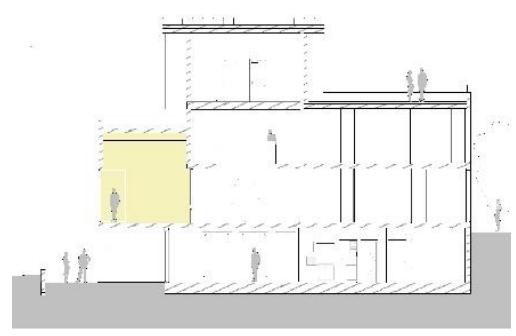

(b) Section

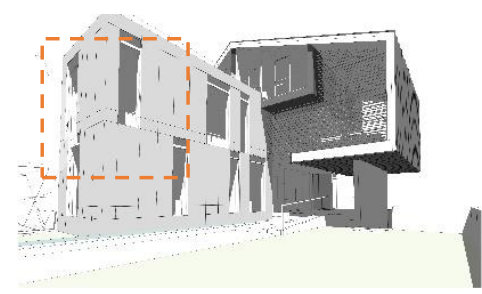

(c) Model

Fig 2. Plan (a), section (b) and a model (c) for investigated office space

Table 1. Variables for the office space and aperture used in the study

\begin{tabular}{cc}
\hline Variables for the space & Variables for the apertures \\
\hline Area: $17.25 \mathrm{~m}^{2}$ & Window dimensions: \\
Room dimension: $5.00 \mathrm{~m} \times 3.45 \mathrm{~m} \times 2.80 \mathrm{~m}$ & 80x200 m (e),160x200 m (s), 80x200 m (w) \\
Visible transmittance of the glazing: $90 \%$ \\
Wall 60\%, Floor: $30 \%$, Ceiling: $70 \%$ & Reduction factor for frame: $90 \%$ \\
No external obstacles & Reduction factor for pollution: $90 \%$ \\
& No shading devices \\
\hline
\end{tabular}


Evaluations of the current visual comfort conditions in the office space and the design options developed for the study are analysed with DIALUX 4.13 simulation program [22]. Two different reference planes (task plane and working plane both with $0.85 \mathrm{~m}$ height from the floor) are created to determine the illuminance level for general and task lighting. The reference planes created in the office space are shown in Fig. 3.

\subsection{Evaluation of the current lighting system in the office space in terms of visual comfort and energy performance}

Visual comfort conditions in the office space are evaluated according to the standard TS EN 124641:2013 considering illuminance level (Em), glare (UGR), uniformity (Uo) and colour rendering index $(\mathrm{Ra})$. The maintained illuminance should not be lower than 500 lux on the reference plane for writing, typing, reading, data processing in the office. The unified glare index (UGR) should not be higher than 19, the maximum value in order to ensure visual comfort conditions in relation to glare in offices. The illuminance uniformity on the reference plane should be minimum 0.60. Colour rendering index value ( $\mathrm{Ra}$ ) for the lamp should be minimum 80 to optimize visual performance.

In order to determine the visual comfort conditions of the workspace, the current lighting system of office created with Fluorescent T8

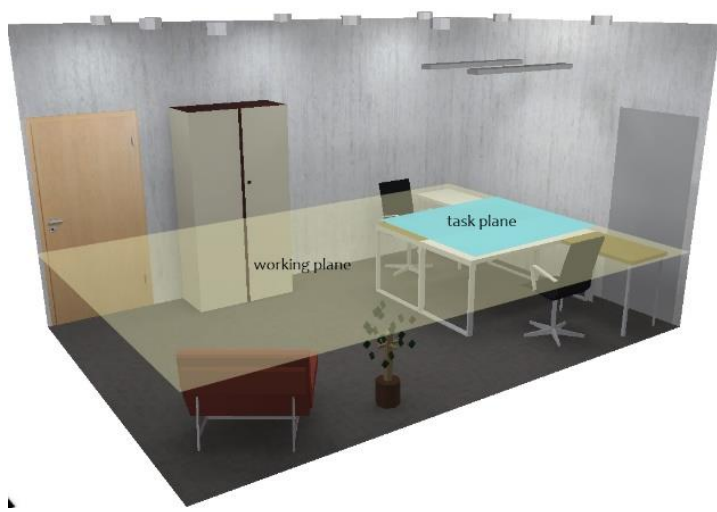

Fig 3. The two reference planes in the sample office space

L18W/830 luminaries is analysed with DIALUX 4.13. Table 2 shows information about artificial lighting system components and the values obtained for the reference planes (working planetask plane) created in the space based on the calculations. According to the results, the maintained illuminance achieved with the existing lighting system, are 213 lux and 237 lux for the working plane and task plane respectively. The uniformity level calculated as 0.69 at the task plane is higher than 0.60, which is the minimum level in the space. The UGR values created for the 2 observers facing each other at a height of $1.20 \mathrm{~m}$ from the floor in the work space are lower than the maximum value of 19 prescribed in the standard.

Table 2. Information about the existing lighting system and the values for visual comfort parameters

\begin{tabular}{|c|c|c|}
\hline \multicolumn{2}{|c|}{ Current artificial lighting system characteristics } & Luminaire-Luminous intensity distribution \\
\hline Lamp Type & Fluorescent & \\
\hline Luminaire Type & Surface-mounted & \\
\hline Luminous Flux & $2700 \mathrm{~lm}$ & \\
\hline $\mathrm{Ra}$ & $80<\ldots<89$ & \\
\hline Luminous Wattage & $36 \mathrm{~W}$ & \\
\hline Lamp Number & 6 & \\
\hline Arrangement & $3 \times 2$ linear order & \\
\hline Total Wattage & $216 \mathrm{~W}$ & - \\
\hline \multicolumn{3}{|c|}{ Visual Comfort Parameters } \\
\hline \multicolumn{2}{|c|}{$\mathrm{E}_{\mathrm{m}}$ (on working plane) } & $213 \operatorname{lux}$ \\
\hline \multicolumn{2}{|c|}{$\mathrm{E}_{\mathrm{m}}($ on table plane $)$} & $237 \operatorname{lux}$ \\
\hline \multicolumn{2}{|c|}{ UGR } & $16-17$ \\
\hline \multicolumn{2}{|c|}{$\mathrm{U}_{\mathrm{o}}($ on table $)$} & 0.69 \\
\hline
\end{tabular}


As a result, it is determined that illuminance level cannot be achieved on the working plane and task plane with the $216 \mathrm{~W}(6 \times 36 \mathrm{~W})$ installed power in the work space and UGR, uniformity and colour rendering index values met the criteria specified in the standard TS EN 12464-1:2013.

Evaluation of the energy performance of a lighting system developed to achieve a sustainable lighting design depends on whether indoor visual comfort parameters have the required values prescribed in EN 12464-1:2013. Although the glare index, uniformity and colour rendering index values are obtained (UGR, $U_{o}, R_{a}$ ) at required level with the artificial lighting system built using $6 \times$ T8 L2x18W (216W total installed power) fluorescent lamps, as the maintained illuminance $\left(E_{m}\right)$ value is not met the standard requirements. So, visual comfort conditions cannot be achieved in the workspace. As a result, energy performance calculation is not done for the current lighting system according to the sustainable lighting design approach indicated in Fig. 1, where meeting visual comfort conditions is a prerequisite to evaluate energy performance of a space.

\subsection{Designing lighting system improving visual comfort and energy performance in the office space}

This study intends to develop a lighting system design, which provide visual comfort conditions and optimize the energy performance. Thus, the lighting system scenarios created in the office space are examined in scope of the lighting concept, lamp and luminaire types. Two lighting concepts, which are general and integrated lighting system given in Fig. 4 are investigated for the office space. As the general lighting express uniform lighting of an entire space without taking specific visual tasks into account, the task lighting describing additional lighting of the workplace are used to meet the lighting demands of specific visual tasks [23]. The various lighting system design proposals having general and integrated (general+task) lighting concept are developed and the effects of these proposals on the lighting energy consumption are evaluated. Furthermore, two kinds of lamp type, which are fluorescent and LEDs the most commonly used in the office building are selected for investigating the effects of the lamp types on the lighting energy performance. The types of the lighting fixtures are preferred as direct and indirect as well.

Providing visual comfort conditions are accepted as a prerequisite for each scenario. Thus the limit value for ensuring prerequisites according to the standard EN 12464-1:2013 are specified that maintained illuminance is 500 lux on the task plane, UGR value is expected to be maximum 19 and uniformity to be 0.6 on task plane and Ra value for lamps selected is expected to be minimum 80 [20]. Lighting system design scenarios and information about the luminaries used to achieve visual comfort conditions in the office space are shown in Table 3.

Visual comfort conditions provided in the office space for all design scenarios are analysed with DIALUX 4.13 simulation program. A general lighting system is recommended in scenarios $\mathrm{S} 1$ and S2 with the goal of achieving maintained illuminance of 500 lux, which is required for functions such as reading, writing etc. in accordance with TS EN 12464-1:2013 standard. In scenarios S3, S4, S5 and S6, both general lighting and task lighting are designed by using different luminaire types. For these scenarios, the maintained illuminances on the working plane and task plane are determined as 300 lux and 500 lux respectively. Based on the calculations, visual comfort parameters for the working plane and task plane, which are expected to be achieved with the scenarios created in this study, are shown in Table 4.

Based on the results, maintained illuminance on working plane and task plane and uniformity values on task plane meet the requirements of the standard TS EN 12464-1:2013 in all scenarios. Except for the scenario S3, UGR values for glare at two eyelevel points in all scenarios are lower than the maximum value prescribed in the standard. 


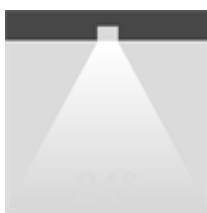

General Lighting System

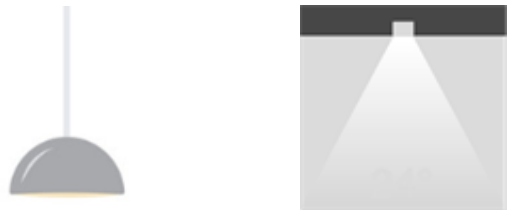

Integrated Lighting System

(Task and General Lighting)

Fig 4. The concept of the artificial lighting system examining in the study

Table 3. Artificial Lighting Scenarios created for the office space

\begin{tabular}{|c|c|c|c|c|c|}
\hline \multicolumn{3}{|c|}{ Artificial Lighting Design Scenarios } & $\begin{array}{l}\text { Luminaire-Luminous } \\
\text { intensity distribution }\end{array}$ & Number of & $\begin{array}{c}\text { Total } \\
\text { Wattage }\end{array}$ \\
\hline $\mathrm{S} 1$ & $\begin{array}{l}\text { Lamp Type } \\
\text { Luminaire Type } \\
\text { Luminous Flux } \\
\text { Ra } \\
\text { Luminous Watt }\end{array}$ & $\begin{array}{c}\text { LED } \\
\text { Direct, } \\
\text { Downlight } \\
1150 \mathrm{~lm} \\
>80 \\
14.5 \mathrm{~W}\end{array}$ & & $\begin{array}{l}16 \text { LED lamps } \\
\text { Linear order } 4 \times 4 \text { on } \\
\text { surface mounted }\end{array}$ & $232 \mathrm{~W}$ \\
\hline S2 & $\begin{array}{l}\text { Lamp Type } \\
\text { Luminaire Type } \\
\text { Luminous Flux } \\
\text { Ra } \\
\text { Luminous Watt }\end{array}$ & $\begin{array}{c}\text { Tubular Fluorescent T8 } \\
(2 \times 18 \mathrm{~W} / 830) \\
\text { Direct, Surface-mounted } \\
2700 \mathrm{~lm} \\
89>\ldots>80 \\
36 \mathrm{~W}\end{array}$ & & $\begin{array}{l}\text { Total } 15 \text { T8 lamps } \\
\text { Linear order } 3 \times 5 \text { on } \\
\text { surface mounted }\end{array}$ & $540 \mathrm{~W}$ \\
\hline S3 & $\begin{array}{l}\text { Lamp Type-1 } \\
\text { Luminaire Type-1 } \\
\text { Luminous Flux-1 } \\
\text { Ra-1 } \\
\text { Luminous Watt-1 } \\
\text { Lamp Type-2 } \\
\text { Luminaire Type-2 } \\
\text { Luminous Flux-2 } \\
\text { Ra-2 } \\
\text { Luminous Watt-2 }\end{array}$ & $\begin{array}{c}\text { LED } \\
\text { Direct, } \\
\text { Downlight } \\
1150 \mathrm{~lm} \\
>80 \\
14,5 \mathrm{~W} \\
\text { Tubular Fluorescent TL5 } \\
(1 \times 21 \mathrm{~W} / 840) \\
\text { Direct, suspended } \\
1925 \mathrm{~lm} \\
>80 \\
21 \mathrm{~W}\end{array}$ & & $\begin{array}{c}\text { Total } 2 \text { TL5 lamps } \\
\text { Suspended } \\
\text { luminaries above the } \\
\text { tables }\end{array}$ & $172.5 \mathrm{~W}$ \\
\hline S4 & $\begin{array}{l}\text { Lamp Type-1 } \\
\text { Luminaire Type-1 } \\
\text { Luminous Flux-1 } \\
\text { Ra-1 } \\
\text { Luminous Watt-1 } \\
\text { Lamp Type-2 } \\
\text { Luminaire Type-2 } \\
\text { Luminous Flux-2 } \\
\text { Ra-2 } \\
\text { Luminous Watt-2 }\end{array}$ & $\begin{array}{c}\text { Tubular Fluorescent T8 } \\
(2 \times 18 \mathrm{~W} / 830) \\
\text { Direct, Surface-mounted } \\
2700 \mathrm{~lm} \\
89>\ldots>80 \\
36 \mathrm{~W} \\
\text { Tubular Fluorescent TL5 } \\
(1 \times 21 \mathrm{~W} / 840) \\
\text { Direct, suspended } \\
1925 \mathrm{~lm} \\
>80 \\
21 \mathrm{~W}\end{array}$ & & $\begin{array}{c}\text { Total } 2 \text { TL5 lamps } \\
\text { Suspended } \\
\text { luminaries above the } \\
\text { tables }\end{array}$ & $330 \mathrm{~W}$ \\
\hline
\end{tabular}


Table 3. Cont'd

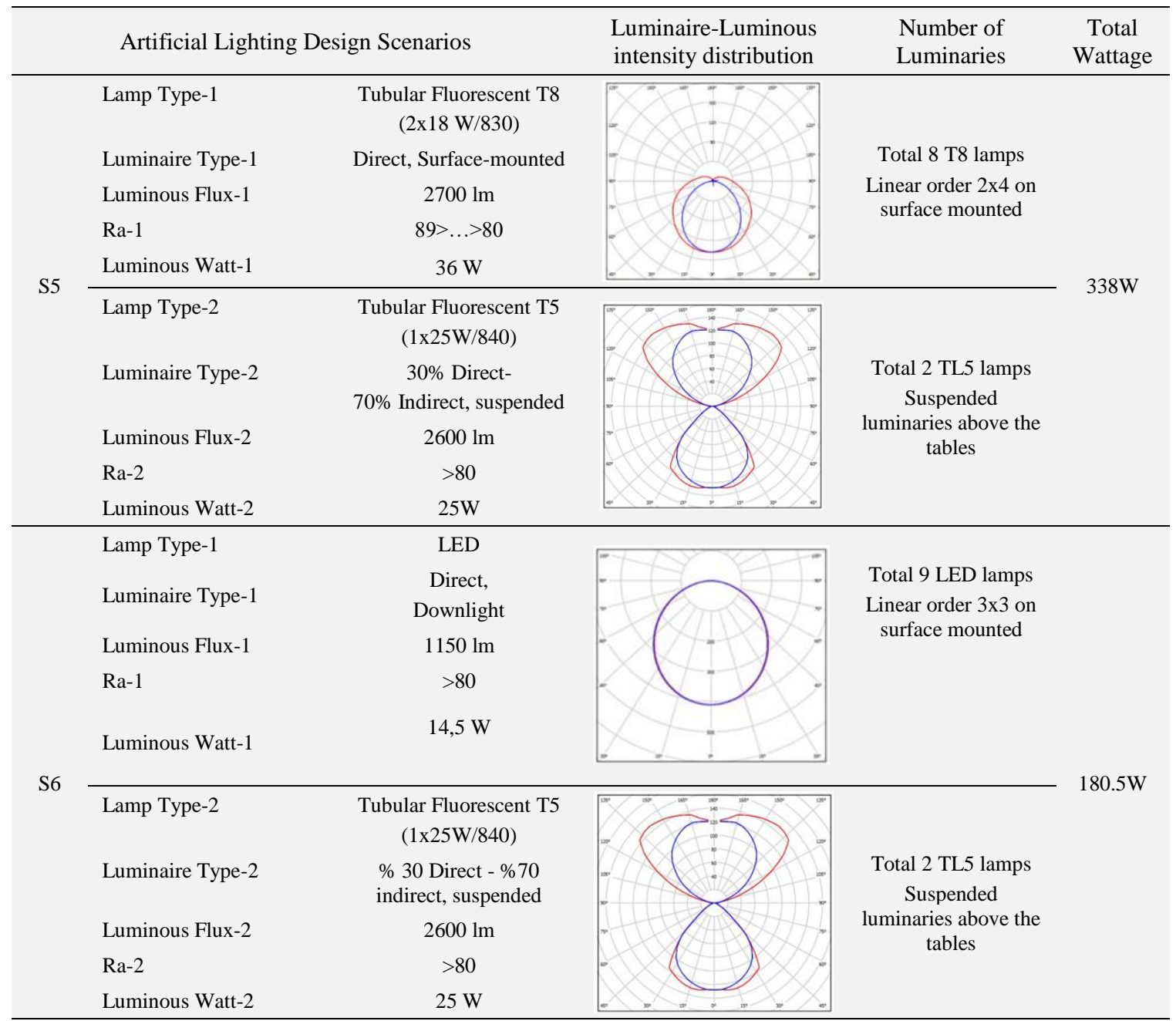

Table 4. Calculated values for visual comfort parameters of the lighting system scenarios created in the study

\begin{tabular}{|c|c|c|c|c|c|}
\hline \multicolumn{2}{|c|}{ Artificial Lighting Scenarios } & \multicolumn{4}{|c|}{ Visual Comfort Parameters } \\
\hline & Description & $\begin{array}{c}\mathrm{E}_{\mathrm{m}} \\
\text { On working plane }\end{array}$ & $\begin{array}{c}\mathrm{E}_{\mathrm{m}} \\
\text { On task plane }\end{array}$ & UGR & $\begin{array}{c}\mathrm{U}_{\mathrm{o}} \\
\text { (on table ) }\end{array}$ \\
\hline S1 & General Lighting $5001 \mathrm{x}$ & 547 lux & $589 \operatorname{lux}$ & 18 & 0.81 \\
\hline $\mathrm{S} 2$ & General Lighting $5001 \mathrm{x}$ & 517 lux & $574 \operatorname{lux}$ & 17 & 0.81 \\
\hline $\mathrm{S} 3$ & $\begin{array}{l}\text { General Lighting } 3001 \mathrm{x} \\
\text { Task lighting } 5001 \mathrm{x}\end{array}$ & 407 lux & $658 \operatorname{lux}$ & 20 & 0.64 \\
\hline S4 & $\begin{array}{l}\text { General Lighting } 300 \mathrm{~lx} \\
\text { Task lighting } 500 \mathrm{~lx}\end{array}$ & $310 \operatorname{lux}$ & $562 \operatorname{lux}$ & 19 & 0.63 \\
\hline S5 & $\begin{array}{l}\text { General Lighting } 300 \mathrm{~lx} \\
\text { Task lighting } 500 \mathrm{~lx}\end{array}$ & $308 \operatorname{lux}$ & $512 \operatorname{lux}$ & 19 & 0.72 \\
\hline S6 & $\begin{array}{c}\text { General Lighting } 300 \mathrm{~lx} \\
\text { Task lighting } 500 \mathrm{~lx}\end{array}$ & $401 \operatorname{lux}$ & 577 lux & 17 & 0.81 \\
\hline
\end{tabular}


As the required maintained illuminance is achieved on the reference planes and the lowest UGR value is met compared to other scenarios to prevent discomfort glare, the highest value of 0.81 for illuminance uniformity is achieved in the scenario S6. Thus, scenario S6 showed the best performance to meet visual comfort conditions within all scenarios. Moreover, the difference between the maintained illuminance values achieved on task plane and surrounding plane in the scenarios S1 and S6 is quite low. Although the maintained illuminance values $\left(E_{m}\right)$ and uniformity $\left(U_{o}\right)$ for reference planes created in the workspace are achieved in the scenario S3, the visual comfort conditions in the office space were not provided with scenario S3 due to the reason that the unified glare index was over the maximum UGR value.

According to the approach developed in this study, it is recommended to evaluate energy performance of the lighting system scenarios that meet visual comfort conditions for a sustainable lighting design. For each scenario that meets visual comfort parameters (S1, S2, S4, S5, S6), the energy requirement of the lighting system are estimated with the detailed calculation steps described in the standard TS EN 15193-1: 2017 and energy performances of the lighting systems in these scenarios are evaluated by comparing. Scenario S3, which has the lowest total installed power for the lighting system (Table 2) is not included in the calculations in accordance with the study approach as in this scenario visual comfort conditions cannot be met in the work space.

In the calculations for lighting energy requirements in the scenarios, constant illuminance factor $\left(F_{c}\right)$ is specified as 1 , since there is no dimmable system in the workspace. The absence factor $\left(F_{a}\right)$ for offices for 2-6 people is 0.3 and the occupancy dependency factor $\left(\mathrm{F}_{\mathrm{o}}\right)$ is taken as 0.9 with a manual control system. The workspace is considered to be occupied between 09:00 - 18:30 hours and annual operating hour for the office buildings is taken as $t_{D}: 2250$ hours and $t_{N}: 250$ hours; in total 2500 hours in the calculations.

In the workspace with no external obstacles and three openings with the dimensions of $80 \times 200 \mathrm{~m}$, 160x200 m, 80x200 m on the east, south and west façades respectively, the areas benefiting from daylight are shown in the Fig. 5. To describe the daylight availability in the office space, the Daylight Factor of the raw building carcass opening $\left(D_{c}\right)$ is found to be $8.15 \%$ depending on the size of the apertures and day lit areas according to the calculation method given at technical report [24]. The daylight efficiency for the sample office space is determined to be strong according to the daylight availability classification based on the daylight factor $(8.15 \%)$. Relevant daylight factor (D) is found as $5.05 \%$ with the addition of window features (light transmittance glazing: 0.9, reduction factor for frame: 0.9 , reduction factor for pollution: $0.9)$ in the calculations.

Daylight dependency factor $\left(\mathrm{F}_{\mathrm{D}}\right)$ is determined according to the daylight supply factor $\left(\mathrm{F}_{\mathrm{D}, \mathrm{S}}\right)$ and the daylight dependent control factor $\left(\mathrm{F}_{\mathrm{D}, \mathrm{C}}\right)$. In the circumstance in which the relevant daylight factor is $5.05 \%$ and the prevalent direction is south for the office space located in Ankara ( $40^{\circ} 00^{\prime} \mathrm{N}, 32^{\circ} 54^{\prime}$ E) and has no shading devices, the daylight supply factor $\left(F_{D, S}\right)$ is 0.781 according to the tables given in the standard TS EN 15193-1: 2017. Daylight dependency control factor $\left(\mathrm{F}_{\mathrm{D}, \mathrm{C}}\right)$ value is determined to be 0.57 based on the expected 500 lux mean maintained illuminance, the manual controlled lighting system and strong daylight availability in the office space. Consequently, with the inclusion of the above-summarized variable values in the calculations, the daylight dependency factor $\left(F_{D}\right)$ of the investigated office space is found to be 0.55 using the formula given in the Eq. (2).

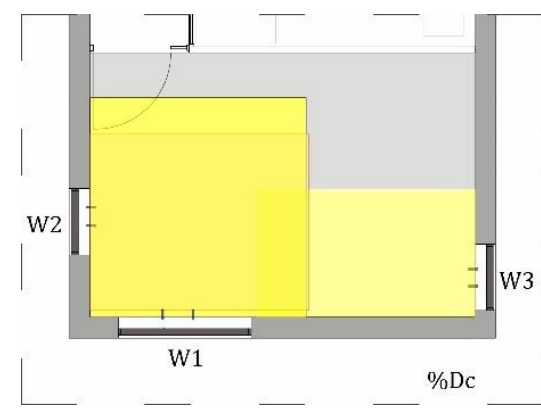

Fig 5. The areas benefiting from daylight in the office space 
The above given values are used as constants in calculations for all scenarios, annual lighting energy requirements of the scenarios varied depending on the installed power which changed depending on the power of the luminaries used in the lighting system. Annual total lighting energy requirements (WL,t/ $\mathrm{kWh}$ ) in the scenarios according to the Eq. (1), are shown in the Fig. 6.

Based on the results obtained in the calculations for the scenarios S1, S2, S4, S5 and S6, which provided visual comfort conditions, annual total lighting energy requirements of the space are 312.9 kWh, 728.5 kWh, 445.2 kWh, 455.9 kWh, 243kWh respectively. The lowest lighting energy requirement in the space is achieved in the scenario S6. The scenario S2 shows the worst performance for lighting energy requirement. Based on the comparison of the scenarios for their visual comfort performances according to the standard TS EN 12464-1: 2013 and for their lighting energy requirements calculated according to the standard TS EN 15193-1: 2017, the design scenario S6 had the optimum performance for sustainable and energy efficient lighting system in the office space. When the energy performances of the scenarios are compared according to lighting concepts, it is also seen that integrated lighting design is more energy efficient strategy than general lighting concept. The results indicate that the lighting energy requirement were reduced $22 \%$ by S6 scenario designing integrated lighting system compared with S1 scenario creating general lighting system. Similarly, by the S4 and S5 scenarios the lighting energy requirement in office space were reduced $39 \%$ and \%37,5 compared with S2 scenario respectively.

Energy performance of a building is determined by adding total energy for standby of the building $\left(\mathrm{W}_{\mathrm{p}, \mathrm{t}}\right)$ to the total energy for lighting which is explained in detail above and calculated separately for each space. According to the calculations, lighting energy performance of a building is shown with the Lighting Energy Numeric Indicator (LENI) value, which indicates annual energy required for lighting per unit area. In this regard, the approach developed for this study and shown in Figure 1 includes the steps that need to be followed to improve energy performance by decreasing LENI value of the building.

\section{Conclusion}

Due to over-consumption of energy resources and increased lighting energy consumption in today's world, sustainability approaches have become very important. Therefore designing energy efficient lighting systems to provide visual comfort conditions or retrofitting of existing lighting systems in line with a sustainability approach have become a necessity.

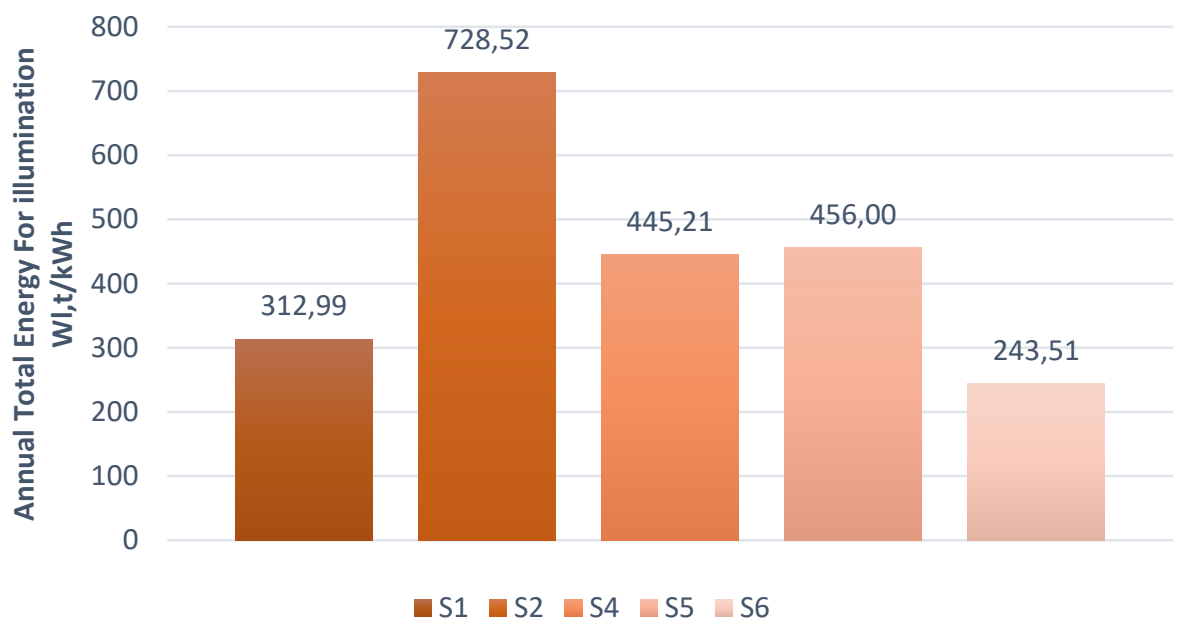

Fig. 6. Calculated total lighting energy requirements for lighting design scenarios 
Considering the share of lighting energy consumption in the total energy consumption, artificial lighting system design decisions in buildings should be evaluated in great detail starting from the early design stages. On the other hand, evaluating lighting systems in existing buildings with a sustainability approach to reduce lighting energy requirements of these buildings will lead to a significant reduction in the consumption of fossil fuels as well.

Creating visually pleasant environment, which supports people's health and activities is one of the main comfort conditions expected in an indoor space. Hence, meeting visual comfort conditions in a space is the most important criteria for a lighting system. In this sense, a lighting system should be designed to avoid any psychological and physiological discomfort for the users depending on the type of the space and function. Evaluation of the energy performance of a lighting system, which does not provide visual comfort conditions, is not possible according to the sustainable lighting design approach.

In this study, an approach for a sustainable lighting system design was suggested in accordance with the standard TS EN 12464-1:2013 which gives criteria to ensure visual comfort conditions in interior and the standard TS EN 15193-1: 2017, which provides a detailed and updated calculation method to determine lighting energy requirements based on the variables. This study intended to develop design solutions to improve lighting energy performance and ensure visual comfort conditions for office spaces for which minimizing lighting energy consumption and meeting visual comfort requirements due to long office hours and expected visual performance is important. Consequently, the performance of the lighting system to be used in the office space was improved with the lighting design alternative creating a visually healthy and comfortable environment and reducing lighting energy requirement.

This study emphasizes the importance of a "sustainable lighting design approach" which starts from the conceptual design stage of buildings and presents strategies to evaluate the lighting systems in existing buildings in terms of visual comfort and energy performance. The developed approach can be applied in future studies, by considering sustainable control strategies and further lighting system alternatives improved with up-to-date luminaires and lamp types. At the same time, it is important that the lighting design alternatives created for enhancing the visual comfort are evaluated by conducting surveys among the occupants.

\section{References}

[1] IEA. (2018). Global energy \& CO2 Status Report. http://www.breeam.com/ BREEAMInt2016 Scheme Document/content/05_health/hea_01_nc. htm. Accessed 5 March 2019

[2] IEA. (2010). Guidebook on Energy Efficient Electric Lighting for Buildings: Annex 45 .http:// www.ieaebc.org/Data/publications/EBC_Annex_45_Guide book.pdf. Accessed 9 March 2019

[3] Li DHW, Lam TNT, Wong SL, Tsang EKW (2008). Lighting and cooling energy consumption in an open-plan office using solar film coating. Energy, 33, 1288-97.

[4] Yu X, Su Y (2015). Daylight availability assessment and its potential energy saving estimation -A literature review. Renewable and Sustainable Energy Reviews, 52, 494-503.

[5] Lombard LP, Ortiz J, Pout C (2008). A review on buildings energy consumption information. Energy and Buildings, 40, 394-398.

[6] Dubois MC, Bisegna F, Gentile N, Knoop M, Matusiak B, Osterhaus W, Tetri E (2015). Retrofitting the electric lighting and daylighting systems to reduce energy use in buildings: A literature review. Energy Research Journal, 6(1), 25-41.

[7] Dubois MC, Blomsterberg $\AA$ (2011). Energy saving potential and strategies for electric lighting in future North European, low energy office buildings: A literature review. Energy and Buildings, 43(10), 2572-2582.

[8] Ahmad RM, Reffat RM (2018). A comparative study of various daylighting systems in office buildings for improving energy efficiency in Egypt. Journal of Building Engineering, 18, 360-376.

[9] Tsangrassoulis A, Roetzel A, Doulos L, Topalis F. Assessing lighting energy saving potential from daylight harvesting in office buildings based on 
code compliance \& simulation techniques: a comparison. International Conference on Sustainable Synergies from Buildings to the Urban Scale, 16-19 October 2017, Greece.

[10] Zinzia M, Mangione A (2015). The daylighting contribution in the electric lighting energy uses: EN standard and alternative method comparison. Energy Procedia, 78, 2663-2668.

[11] Soori PK, Vishwas M (2013). Lighting control strategy for energy efficient office lighting system design. Energy and Buildings, 66, 329-337.

[12] Kaminska A, Ozadowicz A (2018). Lighting control including daylight and energy efficiency improvements analysis. Energies, 11(8), 2166.

[13] Xu L, Pan Y, Yao Y, Cai D, Huang Z, Linder N (2017). Lighting energy efficiency in offices under different control strategies. Energy and Buildings, 138, 127-139.

[14] Lo Verso VRM, Pellegrino A, Aghemo C (2016). The energy performance for lighting in buildings according to the new EN 15193-1: potential energy saving due to different photodimming controls. Energy Procedia, 101, 232-239.

[15] Soori PK, Alzubaidi S. Study on improving the energy efficiency of office building's lighting system design. IEEE GCC Conference and Exhibition (GCC), 2011.

[16] Zografakis N, Karyotakis K, Tsagarakis KP (2012) Implementation conditions for energy saving technologies and practices in office buildings: Part 1. Lighting. Renewable and Sustainable Energy Reviews, 16, 4165-4174.

[17] Duboisa M-C, Gentile N, Amorim CND, Osterhaus W, Stoffer S, Jakobiak R, Geisler-Moroder D, Matusiak B, Onarheim FM, Tetri E (2016). Performance evaluation of lighting and daylighting retrofits: results from IEA SHC task 50. Energy Procedia, 91, 926 - 937 .

[18] Linhart F, Scartezzini JL (2011). Evening office lighting-visual comfort vs. energy efficiency vs. performance?. Building and Environment, 46(5), 981-989.

[19] IESNA. The IESNA Lighting Handbook: Reference \& Application. 10th Edition, New York: Illuminating Engineering Society of North America, ABD, 2011.

[20] TSE (2013). TS EN 12464-1:2013 Light and Lighting of Workplaces: Part1-Indoor Workplaces. https://intweb.tse.org.tr. Accessed 13 April 2015

[21] TSE (2017). TS EN 15193-1:2017 Energy Performance of Buildings-Energy Requirements for Lighting- Part 1: Spesicifations, Module 09. https://intweb.tse.org.tr. Accessed 15 August 2018

[22] DIALux, Light Building Software, www.dial.com.

[23] Ganslandt R, Hofmann H. Handbook of Lighting Design. 1th Edition, ERCO, Germany, 1992.

[24] CEN. (2017). CEN /TR 15193-2 Technical Report: Energy performance of buildings - Energy requirements for - Part 2: Explanation and justification of $\quad$ EN 15193-1. http://tzb.fsv.cvut.cz/vyucujici/46/64_e_stf-1-.pdf. Accessed 9 March 2019

\section{Nomenclature}

$W_{L, t} \quad$ Total energy for illumination ( $\mathrm{kWh}$ )

$P_{n} \quad$ Total power of $\mathrm{n}$ number of luminaires for illumination (W)

$F_{c} \quad$ Constant illuminance factor

$t_{D} \quad$ Daylight time (h)

$F_{o} \quad$ Occupancy dependency factor

$F_{D} \quad$ Daylight dependency factor

$t_{N} \quad$ Daylight absence time (h) 